
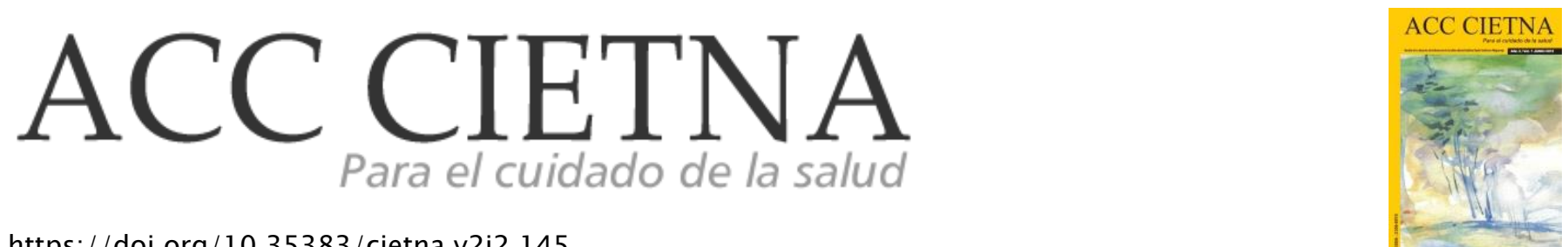

https://doi.org/10.35383/cietna.v2i2.145

\title{
Experiencias del cuidado cultural de madres durante el tratamiento de enfermedad diarreica, Mórrope - 2011
}

\author{
Llonto Acosta Llosdy Jovany ${ }^{1}$, Heredia Mondragón Mary Judith ${ }^{2}$
}

INFORMACIÓN DEL ARTÍCULO
Historia del artículo:
Recibido el 3 de junio de 2015
Aceptado el 15 de noviembre de 2015

\section{Palabras claves:}

Experiencias

Cuidado

Cultura

Diarrea

\section{RESUMEN}

La presente investigación cualitativa con enfoque estudio de caso tuvo como objetivos: describir, analizar y comprender las experiencias de cuidado cultural de las madres durante el tratamiento de la enfermedad diarreica. Las bases conceptuales fueron sustentadas en Wojtyla, Leininger y Waldow. Como escenario se usó el Asentamiento Humano 09 de Febrero - Mórrope. La entrevista semiestructurada abierta a profundidad permitió la recolección de datos, saturándose con seis madres con hijos menores de cinco años. Los datos se procesaron con el análisis de contenido, y aplicación de los criterios éticos y el rigor científico obteniéndose dos categorías: 1) buscando ayuda profesional en salud como acción inmediata para el tratamiento de la diarrea; y 2) cuidando en base a creencias culturales durante el tratamiento de la enfermedad diarreica. Asumiendo como consideración final que las madres cuidan culturalmente a sus niños con diarrea. En primer lugar, acuden al centro de salud, luego utilizan sus plantas medicinales como el orégano, ajo, la hierba luisa, cáscara de granada en combinación con la cáscara de coco; estas plantas por sus ingredientes mejoran la diarrea. También usan objetos culturales como el huevo para sanar el mal del ojo, el periódico y tela negra caliente, material que jalan la "energía negativa" que ha producido la diarrea. Asimismo recurren al "rezo" como ritual cultural para sanar el mal del ojo y otros rezan a Dios para mejorar la enfermedad. Finalmente se automedican con Toban, medicamento contraindicado en el tratamiento de la diarrea infantil.

\footnotetext{
${ }^{1}$ Licenciado en Enfermería. Enfermero contrabajo independiente, Chiclayo, Perú. Email: Illontop@usat.edu.pe.

${ }^{2}$ Licenciada en Enfermería. Docente en la Escuela de Enfermería de la Universidad Católica Santo Toribio de Mogrovejo, Chiclayo, Perú. Email: mheredia@usat.edu.pe
} 
Cultural experiences mothers care for the treatment of diarrhea, Mórrope - 2011

\section{ABSTRACT}

Keywords:

Experience

Care

Culture

Diarrhea
This qualitative research with case study approach aimed to describe, analyze and understand the experiences of cultural care of mothers during treatment of diarrheal disease. The conceptual bases were sustained by Wojtyla, Leininger and Waldow. Mórrope The stage was the Human Settlement February 9. The open-depth semi-structured interview allowed data collection, saturating six mothers with children under five. The data were processed using content analysis, and application of ethical criteria and scientific rigor obtaining two categories: (1) Seeking professional help in health as immediate action for diarrhea treatment; (2) Care based on cultural beliefs during treatment of diarrheal disease. Assuming as final consideration that mothers take care culturally of their children with diarrhea. First they go to the health center, then use their herbs like oregano, garlic, lemongrass, peel Granada in combination with coconut shell; these plants improve diarrhea by their ingredients. Cultural objects are also used as egg to heal evil eye, newspaper and hot black cloth, material that pulls "negative energy" that has produced diarrhea. Also they appeal to "prayer" as a cultural ritual to heal the evil eye and others pray to God to improve the disease. Finally they self-medicate with Toban, contraindicated in the treatment of childhood diarrhea.

\section{Introducción}

La población infantil continúa enfrentando los efectos de las carencias económicas y barreras sociales lo que pone en riesgo su salud. Así, en los países de Asia, África y América Latina mueren alrededor de 3.3 millones de niños por diarrea'. En el Perú, el Ministerio de Salud para el año 2010 consideró como causa de muerte en segundo lugar la enfermedad diarreica, prevaleciendo en poblaciones urbano marginales. El Instituto Nacional de Estadística e Informática (INEI) señala también que entre el $9 \%$ y $13 \%$ de la mortalidad infantil se asocia con la enfermedad diarreica, casi todas las muertes se observan en menores de cinco años y ocurre en países en desarrollo donde la mayor parte se relaciona a diversos factores, lo cual está incrementando el número de muertes².
En el año 2009 la morbilidad por diarrea en menores de cinco años asciende al 14\%, seguida de infecciones respiratorias agudas (IRAS) con $6.8 \% 2,3$.El Ministerio de Salud del Perú en el año 2010 señala en segundo lugar con el $16 \%$ a la enfermedad diarreica dentro de las 10 primeras causas de morbilidad para la etapa infantil; y según el INEI afirma que la diarrea en el Perú durante el primer semestre del año 2010 asciende al 19\%1. En ese sentido, la tasa de morbilidad ha aumentado mínimamente en relación a esta patología persistiendo en la población infantil.

En América Latina, según la Organización Panamericana de la Salud (OPS $)^{4}$, señala que las enfermedades diarreicas constituyen un problema de salud pública en el mundo especialmente en los países en desarrollo donde representan una importante causa de morbilidad y mortalidad en 
niños menores de cinco años. Se ha estimado que en Asia, África y América Latina cada año ocurren más de mil millones de episodios de diarrea'. Además la Organización Mundial de la Salud (OMS), en el año 2008 en su publicación en el Fondo de Naciones Unidas para la Infancia (UNICEF), afirma que la enfermedad diarreica en los primeros cinco años de vida es de 3 episodios por año ${ }^{1}$ y según INEI en el año 2007, los niños menores de cinco años tienen entre 5 a 10 episodios de diarrea al año².

Ciertamente los datos estadísticos demuestran que la enfermedad diarreica constituye un serio problema de salud pública, y el Perú no escapa a esta realidad al ser un país en vías de desarrollo. El Perú presenta factores condicionantes que favorecen la presencia de esta enfermedad, evidenciándose en los estratos sociales habitualmente excluidos como las comunidades urbano-marginales. Si consideramos que las comunidades urbano marginales están incluidas dentro de las categorías zona o área rural entonces es oportuno mencionar que a nivel nacional la incidencia de diarreas en las zonas urbanas y rurales es mayor en los niños de hogares más pobres con el $39.7 \%$ en zona urbana y $31.9 \%$ en zona rural. Según la Encuesta Demográfica de Salud Familiar (ENDES), en el año 2007 la morbilidad por diarrea infantil a nivel nacional es de $71 \%$, siendo en el área fue de un $13 \%$, y el tratamiento de la población rural $75 \%$ y área urbana $64 \%$.

Las estadísticas señalan que las incidencias de diarreas son mayormente en las zonas rurales principalmente en los sectores más vulnerables de nuestro ámbito quienes carecen de recursos económicos y presentan poca accesibilidad a los servicios básicos. Además sus pobladores con diferentes costumbres realizan muchas veces prácticas de recuperación de la salud inadecuadas.

Vásquez4 en su investigación factores socioeconómicos y culturales en reincidencia de enfermedad diarreica, identifica como otros factores de riesgo de salud en el caso de los menores de cinco años, el uso inadecuado de la lactancia materna, uso de biberones, ingesta de alimentos varias horas después de cocinados, ingesta de agua contaminada, falta de lavado de manos, disposición inadecuada de las heces fecales, desnutrición, sarampión, inmunosupresión, introducción reciente de leche de vaca y episodios repetitivos de diarrea aguda 5 . La escasez de oportunidades, la pobreza y falta de cobertura para satisfacer las necesidades básicas deben considerarse como otros factores predominantes que afectan la su salud de los infantes.

Las tasas de morbilidad muestran entonces que las enfermedades diarreicas se han incrementado favorecidas incluso por los diferentes factores de riesgo siendo la patología más frecuente en niños por lo que sus padres en especial las madres buscan diferentes alternativas de solución para protegerlos suscitando en ellas una práctica de hábitos recuperativos o desfavorables.

Eso se deja entrever en una experiencia de pregrado donde el aspecto cultural influye en la salud asumiendo que el control de esta y de la enfermedad obedece a fuerzas sobrenaturales. Tal fue el caso de una madre procedente de la serranía del Perú quien manifestó "mi hijo se enfermó porque le hicieron daño" -haciendo referencia a la brujería-. Otras veces la recuperación se contempla también como dependiente de la voluntad de Dios, "si está de Dios se recuperará, qué hice para que Dios nos castigue de esta forma"; adjudican el haberse opuesto a su Voluntad. Esta situación expone a optar diferentes conductas para recuperar la salud, algunos hacen una combinación de ambas o dejan de lado la medicina científica para utilizar la medicina natural o tradicional a través de remedios caseros, plantas medicinales o acuden al curandero para tratar su salud y otros males.

Otra experiencia de pregrado durante las prácticas comunitarias es el caso de una madre de familia 
que llegó a la consulta médica para el tratamiento de su niño, pues había descontinuado las indicaciones del médico, manifestando: "vi que mejoraba y ya no le di el jarabe", dando origen al interrumpimiento del tratamiento médico $y$ adjudicar la responsabilidad de la salud a fuerzas sobrenaturales; es más frecuente en poblaciones urbano marginales cuyos responsables del cuidado de la salud de sus hijos son madres que carecen de un nivel educativo superior. Como vemos ello cabe cuestionarse si las madres conocen cómo la salud del menor de cinco años está expuesta, por afrontar las circunstancias que involucra el tratamiento de la diarrea, qué prácticas realizan durante este tratamiento, y si siguen con precisión las indicaciones del tratamiento de la diarrea.

Al evidenciarse esta problemática se planteó la siguiente pregunta de investigación: ¿Cuáles son las experiencias de cuidado cultural de madres durante el tratamiento de enfermedad diarreica Mórrope 2011? El objeto de estudio fue las experiencias de cuidado cultural de madres durante el tratamiento de enfermedad diarreica. Se planteó describir, analizar y comprender las experiencias de cuidado cultural de madres durante el tratamiento de enfermedad diarreica, objetivos que permitieron comprender el objeto de investigación.

En la enfermedad diarreica, al ser uno de los problemas de salud más graves que se presenta en poblaciones en desarrollo $y$ al estar asociada principalmente a la mortalidad en menores de cinco años, fue necesario comprender las experiencias de cuidado cultural que presentan las madres durante el tratamiento de la misma que brindan a sus hijos, además nos permite cumplir uno de los objetivos de desarrollo del milenio del Estado Peruano, el cual es reducir la mortalidad en los niños menores de cinco años.

Igualmente, la investigación favorecerá el desarrollo de otras investigaciones relacionadas con el objeto de investigación, pretendiéndose que estos resultados sean conocidos por los directivos de las instituciones educativas, responsables del programa de vaso de leche, personal de salud, así como por estudiantes de enfermería que laboran de manera directa con la población infantil, de tal forma que la sensibilización permita implementar programas educativos individuales y colectivos dirigidos a las madres para mejorar sus actitudes en relación al cuidado cultural de la salud durante el tratamiento de la enfermedad diarreica, considerando siempre sus características socioculturales que interactúan en ellas.

\section{Metodología}

La investigación se desarrolló como cualitativa, descriptiva, buscando interpretar lo que es, relacionándola a concesiones $\mathrm{o}$ conexiones existentes ${ }^{5}$. Y como estudio de caso permitió comprender y analizar los fenómenos más relevantes para el desarrollo de la investigación?. Los participantes fueron seis madres de familia con hijos menores de cinco años obtenidas por saturación que viven en el Asentamiento Humano 09 de Febrero - Mórrope. Se recolectaron los datos mediante la entrevista semiestructurada abierta a profundidad, previa firma del consentimiento informado, durante el mes de marzo a junio de 2012. A todos los sujetos de investigación se les garantizo su anonimato y confidencialidad. Para las madres se usaron el nombre de flores.

En el procesamiento de los datos se utilizó el análisis de contenido?. Según el criterio de analogía fueron consideradas las similitudes o semejanzas, que existan entre estas de acuerdo a sus etapas: En el pre análisis se transcribió y organizó en forma fidedigna, las entrevistas hechas a las madres que Mórrope, en el programa de Microsoft Word. Para la viven en el Asentamiento Humano 09 de Febrerocompletamente detallada de las entrevistas, para ir codificación se realizó una lectura minuciosa y descartando los datos que fueron útiles para la investigadora, estableciéndose los discursos y unidades significativas, luego se fue moldeando 
los discursos en un lenguaje claro y que sería entendido llegando a la categorización en esta etapa se accedió a examinar la información obtenida a través de sus tres etapas que posteriormente se confrontará con la literatura para dar significado a todo lo dicho en las entrevistas y lograr los objetivos planteados.

En todo el proceso de investigación se aplicaron los criterios éticos ${ }^{8}$ y el rigor científico ${ }^{9}$.

\section{Resultados, análisis y discusión}

Categoría I.- Buscando ayuda profesional de salud como acción inmediata para el tratamiento de la diarrea.

Categoría II.- Cuidando en base a creencias culturales durante el tratamiento de enfermedad diarreica.

- Las plantas medicinales como alternativa de solución.

- Uso de objetos culturales influenciados por costumbres y creencias.

- El "rezo" como ritual cultural.

- Ante la desesperación, la automedicación como una alternativa de solución.

Las madres participantes del estudio, en el proceso de solucionar los problemas de salud de sus hijos utilizan creencias y costumbres adquiridas de su entorno personal, familiar y cultural; ellas poseen un conocimiento empírico producto de las experiencias vividas como parte del cotidiano familiar y transmitida por sus antecesores de generación en generación. Para Waldow ${ }^{10}$, las madres asumen creencias culturales y religiosas de diferentes condiciones sociales conllevándolas a vivenciar experiencias de cuidado cultural.
Categoría I.- Buscando ayuda profesional de salud como acción inmediata para el tratamiento de la diarrea.

La enfermedad diarreica ocurre por la falta de prácticas saludables y acompañan con frecuencia a los niños de sectores desprotegidos de nuestra sociedad'1. Al ser infecciosa esta enfermedad necesita de un tratamiento medicamentoso para su erradicación. Por ello las mamás se caracterizan porque respetan las opiniones en su comunidad y han aprendido que al acudir al profesional de salud van a curar a sus hijos de la enfermedad, en especial cuando la diarrea es infecciosa o hay presencia de deshidratación. Como se refleja en los discursos:

"Primero lo llevo al centro de salud para que el doctor le recete...". (Azucena)

"Acudo al centro de salud para que mi niña reciba atención del médico. Allí las enfermeras me proporcionan sales de rehidratación oral". (Rosa)

Las mamás influenciadas por costumbres de la comunidad encuentran la solución inmediata al acudir al centro de salud, tienen confianza con el médico y la enfermera, también en los medicamentos que reciben para el tratamiento de esta enfermedad. Ciertamente su conducta obedece que lo aprendido de su cultura es mediante la interacción social con otras personas en la sociedad ${ }^{2}$. Así mismo, respetan el aprendizaje que no ha sido enseñado de manera intencional por otros pobladores, pues lo aprendido no es enseñado intencionalmente, ni tampoco son conscientes de estar aprendiéndolo ${ }^{12}$.

En este sentido, las diferentes situaciones que las madres afrontan durante los cuidados culturales proporcionados a sus niños, va de acuerdo a la realidad de sus costumbres, quieren generarles acciones positivas para mantenerlos, protegerlos y ejercer un mejor control de su salud previniendo 
así circunstancias que pongan en riesgo su bienestar y vida.

Categoría II.- Cuidando en base a creencias culturales durante el tratamiento de la enfermedad diarreica.

Las prácticas realizadas en los diferentes aspectos de la vida influyen en los pensamientos $y$ decisiones de las madres para mejorar el bienestar de sus hijos como una alternativa de solución inmediata a la enfermedad diarreica. Las creencias tienen su propia lógica, coherencia, allí radica la fuerza interna que materializa la fe del ser humano ${ }^{12}$. Por ello, las madres experimentan sus creencias culturales como un modelo basado en la fe creada por su propia costumbre donde no necesita de una demostración y nunca se le exigirá un fundamento de tipo racional, situaciones apreciadas en las siguientes subcategorías:

-Las plantas medicinales como alternativa de solución.

Las madres influenciadas por sus creencias culturales manipulan diferentes plantas medicinales para recuperar la salud de sus hijos. Estos productos forman parte de la medicina tradicional que el hombre ha encontrado utilidad, ha descubierto en ellas beneficios que le ayudan a satisfacer sus necesidades con la capacidad de aliviar enfermedades ${ }^{13}$.

Estos vegetales tienen productos llamados principios activos, sustancias que ejercen una acción farmacológica, beneficiosa o perjudicial sobre el organismo vivo ${ }^{13}$. Poseen una variedad de constituyentes químicos que ejercen un efecto innegable en el ser humano y que al aplicarse por conocimiento empírico su magnitud de eficacia puede extralimitarse arriesgando la vida de la persona.

Tales beneficios hacen que las plantas medicinales sean utilizadas con predilección en base a lo aprendido, experiencias positivas de sus ancestros. Dada las circunstancias las madres de familia confían y utilizan las plantas medicinales durante el cuidado de sus hijos que padecen de diarrea afirmando que les curó la enfermedad. Por ello, cuando se les pregunta de quién aprendió esto aluden a una socialización con sus familiares o allegados:

"Cuando se enferma mi hijo de la diarrea, le hiervo la cáscara de la granada con la cáscara de coco (...) esta costumbre me lo enseñó mi bisabuela y la utilicé para mi hijo, pues dije voy a probar y funcionó...". (Margarita)

\section{"Cuando no tengo dinero le preparo un remedio} casero (...), así le curaba la diarrea, esta costumbre me lo enseñó mi madre". (Rosa)

Lo vertido por las madres puntualiza que la escasez de dinero influye en la decisión por un cuidado terapéutico basado en plantas medicinales. Cuando el Seguro Integral de Salud (SIS) no realiza el aporte íntegro del tratamiento para la diarrea, el familiar del niño se responsabiliza de la compra de algunos medicamentos, recurriendo por escasa condición económica a la utilización de las plantas medicinales, alejando así la oportunidad de una atención integral por personal profesional.

De las plantas medicinales utilizadas por las madres, es rescatable la utilización del orégano, ello precisa ser comprendido desde las propiedades que poseen para poder recomendar su uso adecuado y fortalecer el cuidado cultural que brindan las madres de familia en el hijo que experimenta diarrea.

El orégano (origanum Vulgare) es una planta herbácea, perteneciente a la familia lamiaceae aromática. Su utilización primordial son las hojas. Este vegetal tiene principios activos ricos en timol y carvacrol.

El timol tiene una sustancia cristalina incolora, con olor característico que está presente en los aceites 
esenciales del orégano. Las propiedades que posee según Sellar ${ }^{13}$, son: cicatrizante, antiinflamatorio, antiséptico, expectorante y analgésico. El timol posee ventajas por las propiedades que conserva, razón por la cual las madres lo usan en el cuidado que han brindado a sus hijos para aliviar el proceso de diarrea, incluso desconociendo los riesgos de su uso de manera empírica.

El uso del timol es adecuado en los casos de diarrea, por ello a continuación se establece la relación de las diferentes plantas medicinales que utilizan las participantes con el tratamiento farmacológico. Así, los antibióticos como el sulfametoxazol combinado con la trimpetropina, el ciprofloxacino, furazolidona, ampicilina, vancomicina y metronidazol son indicados en el tratamiento de la diarrea cuando se aplica el Plan "C" por su propiedad bactericida y el timol por su propiedad antiséptica genera el mismo efecto. Así mismo, indican algunos antiinflamatorios tales como el ibuprofeno. De esta forma el timol genera un resultado similar, según Saldierna ${ }^{14}$, es antiinflamatorio y cicatrizante.

El carvacrol es un compuesto químico que se encuentra en los aceites esenciales del orégano; líquido incoloro soluble en agua y en etanol. Tiene propiedades antisépticas, anestésicas, antiinflamatorias, cicatrizantes, antirreumáticas, expectorante y antidiarreico ${ }^{14}$. Su uso es favorable, de allí surge que este vegetal sea elegido por las madres para curar de la diarrea a sus hijos.

A este aporte Sellar ${ }^{13}$, rescata la propiedad rehidratante durante el tratamiento de la enfermedad diarreica. También las madres proporcionan abundantes líquidos a sus hijos durante la pérdida de líquidos y electrolitos, sin embargo, estos no poseen una solución salina isotónica con glucosa en caso de deshidratación. Por ello la Organización Mundial de la Salud en el Plan "A", "B" y "C", recomienda utilizar durante el tratamiento las sales de rehidratación oral (SRO), teniendo en cuenta que estas contienen cloruro de sodio, cloruro de potasio, citrato trisódico dihidrato, glucosa anhídrida para la conservación de glucosa-sodio en la mucosa del intestino delgado ${ }^{11}$.

Se debe rescatar que las propiedades que curan la diarrea provienen tanto del carvacrol como del timol, ambos coinciden específicamente en ser cicatrizantes, antisépticos y antiinflamatorios, además de tener la propiedad de ser un regulador hidroelectrolítico ${ }^{14}$.

Otra planta medicinal preferida por las participantes durante el cuidado a menores de cinco años que padecen de diarrea es el ajo, de acuerdo a lo vertido en el siguiente discurso:

"(..) le preparo remedio casero, cocino el orégano con un diente de ajo en $1 / 2$ taza de agua". "Le doy a tomar a mi hijo una cucharada tres veces al día, por tres días, así le curaba la diarrea, (...)". (Rosa).

Como deja entrever el discurso el orégano continua siendo utilizado pero esta vez combinado con el ajo. Esta planta herbácea denominada como (Allium Sativum), pertenece a la familia liliácea. Su utilización principal es el fruto y su principio activo es un constituyente químico denominado alicina ${ }^{14}$.

La alicina tiene un poder tóxico compuesta por azufre. Las propiedades que posee es antiinflamatorio, antihemorrágico, antiséptico y antiparasitario ${ }^{14}$. La alicina tiene propiedades: bacteriostática, bactericida y antiséptica; preferida por las madres por su fácil preparación y tener los vegetales a disposición.

También las madres hacen uso de costumbres y creencias, cuando perciben que sus hijos no mejoran del proceso diarreico, condiciones que se aprecian en las siguientes subcategorías:

-Uso de objetos culturales influenciados por costumbres y creencias.

De acuerdo al contexto cultural las madres al ver que sus hijos no mejoran hacen uso de creencias y de objetos culturales, definidos como el exceso 
de presencia otorgándole un significado más allá de su función ${ }^{15}$. Este exceso no depende ni de una fuerza mágica de los objetos, ni de las necesidades vitales de los sujetos, sino de la ideología subyacente en cada cultura. Esto significa que diferentes ideologías producen desiguales prácticas, otorgándoles otro estatuto simbólico y a los sujetos diferentes modos posibles no necesarios de subjetivación.

Es importante resaltar que el uso de objetos culturales por las madres se debe al valor significativo y simbólico conferido por sus ancestros, según sus creencias tienen la idea que los curará de la diarrea, estos objetos no tienen un sustrato material, ni una significación espiritual15. En este sentido, el objeto cultural se presenta físicamente bajo una apariencia sensible, permitiendo representar un acto simbólico incorporando una serie de ideas, rezos, valores, costumbres, logrando en el pensamiento de las madres una realidad distinta para priorizar los significados asociados a la forma material, evidenciado por el uso del huevo, trapo negro caliente y papel periódico para salvaguardar la salud del infante:

"Cuando no mejora mi hijo, me acuerdo de las costumbres de mi madre (...) entonces empiezo a jalarlo con huevo para curar la diarrea y con este se cura. EL huevo se vuelve como agua, después de utilizarlo, lo boto a la acequia". (Azucena).

"También para curar la diarrea le paso un huevo de gallina luego lo entierro". (Amapola).

Para Osorio ${ }^{16}$, el huevo es como una esponja que absorbe todas las cargas negativas del cuerpo. Viene de una creencia cultural muy antigua, utilizado para curar el susto, el mal ojo o cuando el niño está "ojeado". Según Leininger, las participantes conservan los cuidados culturales que brindan a su familia como valores relevantes para alcanzar el bienestar de sus hijos ${ }^{12}$.

-El "rezo" como ritual cultural
Rezar involucra pedir algo con fe, es decir, la aceptación de una verdad que no puede demostrarse o probarse mediante el razonamiento lógico ${ }^{15}$. Y las creencias en las madres las expresan como actos de fe y esperanza, actos que les genera confianza, encuentran sentido a la vida transformándolos en valor, obediencia, identidad, entrega personal, ayuda y aceptación incondicional, pues creen que la utilización de rituales sagrados curará a sus hijos de la enfermedad diarreica. Estas costumbres y experiencias adquiridas se relacionan con el poder que ejerce la cultura en sus propios pensamientos cuya influencia viene de familiares más cercanos:

"Mi suegra me manifestaba que la lleve a santiguar, pues ella tiene la idea que cuando un niño está con diarrea está ojeado y necesita ser santiguado, dejo que lo santigüe para evitar que mi suegra se enoje".(Rosa).

"Cuando no mejora mi hijo me acuerdo de las costumbres de mi madre (...), ella acostumbraba hacer los rezos. Yo no creo en los rezos, pero si dejo que lo realicen."(Azucena).

Costumbres como rezos o signarse reciben influencias por ideas o pensamientos negativos, creen que hay personas que inducen el mal del ojo por la mirada, apartando a sus hijos de las personas extrañas con el fin de evitar asustarlos o reciban el "mal de ojo", traspasando a la enfermedad diarreica.

Otra de las creencias arraigadas durante los cuidados para curar la diarrea de sus hijos son las plegarias o rezos, estos son utilizados como un ritual en diferentes sectores de la sociedad de acuerdo a la condición socioeconómica, ubicación geográfica y procedencia rural o urbana de las personas ${ }^{16}$. Las madres son conscientes que es una práctica común presenta diarrea por "mal de ojo".

Los rituales son realizados por la persona que sabe rezar, poseyendo un conocimiento no científico, 
considerándola como orante, santiguadora, para alejar los males del niño y lo realizan cuando especialista de la medicina tradicional, la palabra rezador tiene poder ${ }^{16}$. Las madres durante los cuidados culturales que brindan usan estas costumbres y tienen la idea que cuando un niño está con diarrea está ojeado y debe ser santiguado para curarlos.

Podría afirmarse, desde la teoría de Leininger, que las madres conservan los cuidados espirituales en su familia como valores relevantes, con el fin que alcancen bienestar ${ }^{12}$. Sin embargo, no siempre se obtienen resultados satisfactorios por lo cual las madres hacen uso de la automedicación emergiendo la siguiente subcategoría:

-Ante la desesperación, la automedicación como una alternativa de solución.

Las madres, de acuerdo a la realidad de su cultura nuevamente, son influenciadas por sus tradiciones culturales y ante la desesperación en el proceso de solucionar inmediatamente la enfermedad diarreica de sus hijos concurren a la automedicación.

Ciertamente la enfermedad diarreica es fácilmente identificable, de ahí que su comportamiento inicial sea acudir al médico para buscar una solución o utilizan sus costumbres folclóricas heredadas de sus ancestros, pero al percibir que la diarrea continúa acuden a la automedicación como una alternativa final de solución. Según la Organización Mundial de la Salud (OMS), la automedicación es el uso irracional y descontrolado de fármacos sin ningún tipo de precaución ni respaldo farmacéutico ${ }^{17}$.

Al respecto, Eladi ${ }^{18}$ señala varios factores influyen en este tipo de conducta destacando la presión de grupo o de propios familiares que les ofrecen una alternativa para la solución de problemas basados en su propia experiencia, los cuales ignoran por completo el riesgo que implica la automedicación. Esta realidad es reafirmada por las madres, quienes han aprendido conductas, valores $y$ creencias de una sociedad influenciadas por situaciones familiares para utilizar la automedicación con confianza durante el cuidado que brindan a sus hijos. Tal es el caso de la utilización del medicamento Toban, como se ilustra en los siguientes discursos:

“(..) voy a la botica a comprar "Toban", no sé qué contiene la vecina me enseñó (...) le daba cada 8 horas por dos días solamente un $1 / 4$ tableta, menos de la $1 / 2$ y le quitó la diarrea. (Azucena).

"Le doy la Toban, los vecinos me recomendaron, lo compro en la farmacia es de 250 miligramos, le doy $1 / 4$ cada 8 horas por dos días con este se mejoró, la pastilla Toban lo curó de la diarrea". (Begonia)

Por cierto, el medicamento Toban es el nombre comercial de un antidiarreico que disminuye la motilidad e inhibe el peristaltismo intestinal, no debe administrarse en niños menores de seis años por reacciones alérgicas y se administrar con prescripción médica ${ }^{19}$. Las madres al actuar de acuerdo a sus creencias, costumbres culturales y situación de salud de los hijos, no prevén los riesgos o efectos colaterales que ocasiona este medicamento, coincidiendo con Castells ${ }^{19}$, al usar el toban exponen a sus hijos a riesgos como: reacciones alérgicas, nauseas, vómitos, sequedad de boca y estreñimiento.

\section{Conclusiones}

1. Las experiencias de las madres de familia durante el cuidado de la enfermedad diarreica a sus hijos actúan con confianza, incorporando experiencias de acuerdo a su conducta, valores y creencias. Toman como primera la opción de acudir al centro de salud buscando ayuda profesional, luego hacen uso de sus creencias culturales y usan plantas medicinales, objetos culturales, el "rezo" y la fe en Dios, sin embargo ante la continuación de la te, automedican a los hijos. 
2. Las participantes en sus experiencias proporcionan soluciones a base de plantas medicinales, aprendida mediante la socialización de sus antepasados para recuperar de la diarrea a sus hijos. El uso de plantas medicinales forma parte de la medicina tradicional las mismas que ejercen acción farmacológica empíricamente beneficiosa o perjudicial en el organismo del ser humano especialmente cuando se trata de niños y por estar alejadas de la atención por un profesional de salud por falta de recursos económicos, factor decisivo que conlleva a elegir este tipo de tratamiento.

3. Asimismo, las madres utilizan objetos culturales dándoles un valor significativo y simbólico, de acuerdo a sus creencias. Poseen la idea que van a curar a sus hijos de la diarrea. En este sentido el objeto cultural se presenta físicamente bajo una apariencia sensible permitiendo representar un acto simbólico incorporando una serie de imágenes, valores, creencias culturales, logrando en el pensamiento de las personas una realidad distinta para priorizar los significados asociados a la forma material. También para curar la enfermedad diarreica las madres utilizan objetos culturales como el huevo, trapo negro caliente y papel periódico para salvaguardar la salud del infante; influenciadas por costumbres arraigadas de su lugar de origen y de sus padres.

4. Las participantes durante los cuidados culturales que brindan a sus hijos tienen la idea que cuando un niño está con diarrea "está ojeado", por ello, utilizan el ritual del "rezo" donde una persona experta de la comunidad lo santigua para curarlos del "mal de ojo" que le produce diarrea. De acuerdo a su creencia religiosa también rezan y le piden perdón y ayuda a Dios.

5. Así también las madres están influenciadas por sus conductas, valores y creencias recurriendo a la automedicación en el proceso de solucionar inmediatamente la enfermedad diarreica y al no observar que sus niños mejoren con las plantas medicinales y rezos, sumado a su inexperiencia y bajo nivel educativo, desconocen que al aceptar o buscar la automedicación como una alternativa de solución, conlleva a consecuencias desfavorables en la salud de sus hijos. Comúnmente los automedican utilizando el medicamento Toban, sin embargo ellas desconocen la composición química del medicamento, haciendo uso irracional y descontrolado conduciendo a los efectos colaterales como es la reducción de la motilidad intestinal, además reduce la secreción de fluidos y electrolitos y aumenta la absorción de agua en el organismo de un menor de cinco años y puede causarle distensión abdominal, ilio paralítico, con lo cual agravaría más la enfermedad.

\section{Bibliografía}

1. Espinoza B. Viner, [base de datos en línea].Perú D.F: Prevención de las Diarreas aguda en niños menores de 5 años AA.HH. Jorge Velásquez Portocarrero en el periodo de Enero 2010 Coronel Portillo-Pucallpa-Ucayali-Perú; 2010 [acceso 30 de Octubre de 2011]. Disponible en: http://www.slideshare.net/espinozabazan/estadi stica-basica-prevencion-de-las-diarreasagudas-en-nios-menores-de-5-aos

2. Ministerio de Salud [base de datos en línea].Perú D.F: Dirección General de Salud de las Personas; 2009[acceso 10 de setiembre de 2011]. Situación de Salud de la Niñez Peruana Disponible en: http://www.slideshare.net/Cuerpomedicoinsn/sit uacin-de-la-salud-infantil-en-el-per

3. Instituto Nacional de Estadística- INEI [base de datos en línea].Perú D.F: Encuesta Demográfica y de Salud Familiar; 2009 [acceso 11 de setiembre de 2011]. Ley de Organización de Funciones del Instituto Nacional de Estadística e Informática Disponible en: http://www.measuredhs.com/Pubs/Pdf/FR242/F R242.pdf.

4. Vásquez R. A. María, Factores socioeconómicos $y$ culturales en reincidencia de enfermedades 
diarreicas agudas en niños menores de 5 años, Lambayeque, Perú; 2010.

5. Lupicino I, Metodología de la investigación cualitativa, Primera Edición, España: ALJIBES A.L; 2003.

6. Menga Ludke e Marli E. D. A. André. El Estudio del Caso: Su potencial en Educación; Traducción de Lucía Aranda Moreno; Doctora en Enfermería P.P.T.C.- UNPRG; 2009.

7. Bardin, L. "Análisis de contenido", Primera edición, editorial; 2009.

8. Sgreccia E, Manual de Bioética: Fundamentos de ética biomédica, Editorial Loyola. Brasil; 2010.

9. Morse J, Asuntos críticos en los métodos de investigación cualitativa, Primera Edición, Editorial Universidad Antioquia-Colombia; 2008.

10. Vera W, Cuidar expresión humanizadora, Primera Edición, Editorial Nueva Palabra, México; 2008.

11. OPS/OMS. Ministerio de Salud. Manual Clínico para el Aprendizaje de AIEPI en Enfermería, Washington-EE.UU; 2009.

12. Marriner T- Railer, Modelos y Teorías en Enfermería, Quinta Edición, México. Editorial Harcourt Brace; 2008.

13. Sellar W, Guía de Aceites Esenciales, Quinta Edición, Editorial EDAF.S.L, Madrid- España; 2009. 14. Saldierna J, Recetario de Hierbas y Plantas medicinales, Primera Edición, Editorial México, S.A. Lima-Perú; 2000.
15. Kozier B, Erb G, Blais K, Wilkinson J. Fundamentos de Enfermería, Quinta Edición Editorial Madrid: McGraw-Hill/Interamericana; 2008.

16. Osorio R, [base de datos en línea]. México: Entender y Atender la Enfermedad. Los saberes maternos frente a los padecimientos infantiles; 2009[acceso 28 de setiembre de 2013], Disponible en:

http: / / books.google.com.pe/books?id=MCAOn $1 \mathrm{vbkC \& pg}=\mathrm{PA} 191 \& \mathrm{dq}=$ definicion + del + huevo $+p$ ara + jalar + la + enfermedad $\& \mathrm{hl}=\mathrm{es}-$

$419 \& \mathrm{sa}=X \& \mathrm{ei}=-$

sJVUtCQMpDI9QTOqoGACg\&ved=0CC4Q6AEw

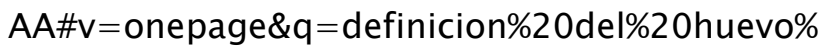
20para\%20jalar\%20la\%20enfermedad\&f=false

17. Serrano M, [base de datos en línea].Madrid: La Educación para la Salud del Siglo XXI, Comunicación y Salud; 2010 [acceso 20 de Junio de 2012],

http:/ / books.google.com.pe/books?id=VxHx8drj $x$ OUC\&pg $=$ PA445\&dq=Automedicacion:ORGANIZ $A C I O N+M U N D I A L+D E+L A+S A L U D \&$ $\mathrm{hl}=\mathrm{es}-419 \& \mathrm{~s} \mathrm{a}=\mathrm{X} \& \mathrm{e} \mathrm{i}=\mathrm{s}-\mathrm{h}$ a U q $7 \mathrm{iBZ}$ O 0 9gT_6oDwBg\&ved=0CCwQ6AEwA $\mathrm{A} \# \mathrm{v}=$ onepage $\&$ $\mathrm{q}=$ Automedicacion\%3AORGANIZACION\%20MUN DIAL\%20DE\%20LA\%20SALUD\&f=false

18. Eladi J, March M, Farmacología Ocular, Segunda Edición, Editorial Barcelona; 2010.

19. Castells S, Hernández M, "Farmacología en Enfermería" Harcourt/Océano, Editorial España; 2009. 